\title{
Effects of experimental coral disturbance on the structure of fish communities on large patch reefs
}

\author{
Andrew R. Lewis \\ Department of Marine Biology, James Cook University of North Queensland, Douglas, Queensland 4811, Australia
}

\begin{abstract}
Communities of reef fishes on 10 large isolated patch reefs or 'bommies' (108 to $267 \mathrm{~m}^{2}$ ) were monitored at 1 to 2 mo intervals over 1 yr, and then the hard corals on 5 of the bommies were physically disturbed by breaking the colonies into small pieces with a mallet. Monitoring continued for a further year after the disturbance. Coral cover at the impacted bommies decreased from -66 to $-29 \%$ by the end of the study, while coral cover had increased by $5 \%$ in the same period at the control bommies. There were significant declines in specjes richness and total abundance of fishes on the impacted bommies, but multivariate analyses showed that the disturbance had no significant effect on spatiotemporal patterns of adult relative abundance and larval recruitment at the community level. Effects of disturbance on the abundance and species richness of 6 families and 8 distinct ecological categories of fishes were also examined. There were significant declines in the abundance of 1 family (the Chaetodontidae) and 1 ecological category (water column/substratum feeding Pomacentridae), and significant declines in the species richness of 2 families (the Apogonidae and Scaridae) and 1 ecological category (invertebratc feeders). Although coral disturbance did effect some elements of the fish communities, it appears that patterns of spatial heterogeneity in the underlying hard substrata at each bommie were also important determinants of fish community structure. Hence, historical patterns of coral growth and substrate consolidation, together with the contemporary coral community, can affect the structure of fish communities on these large patch reefs. Further studies of fish-habitat associations, together with field experiments which manipulate both the underlying substratum and the abundance of live corals, will be necessary to determine the relative importance of each of these habitat characteristics to reef fishes.
\end{abstract}

KEY WORDS: Coral reef fish - Habitat disturbance $\cdot$ Recruitment - Community structure BACI design . Multivariate $\cdot$ Linear mixed-eftects model $\cdot$ Bio-indicator

\section{INTRODUCTION}

Many coral reefs throughout the world are subject to recurring disturbance by tropical cyclones and crown of thorns starfish Acanthaster planci outbreaks (Done 1992). Although these events often cause widespread coral mortality, they also contribute to the maintenance of high species diversity in the coral community by continually making new space available for settlement (Tanner et al. 1994). Disturbance events often occur more frequently than the time necessary for the development of an equilibrium community, so coral assemblages are characterised by a continual cycle of distur-

•E-mail: andrew.lewis@jcu.edu.au bance and recovery (Tanner et al. 1996). Short-lived pioneer species are abundant soon after disturbance and continue to be represented throughout the development period, while slow-growing, longer lived forms gradually increase in abundance with time (Tanner et al. 1994).

Large numbers of fishes live close to the surface of coral reefs, and the spatial structure of the substratum or the composition of the coral community can affect the abundance and composition of the associated fish community (Luckhurst \& Luckhurst 1978, Bell \& Galzin 1984, Sale \& Douglas 1984, Hixon \& Beets 1993). This is evident at a number of spatial scales, from zones hundreds of meters wide within whole reefs (Green 1996, Ormond et al. 1996), down to individual coral heads less than $1 \mathrm{~m}$ in diameter (Williams \& Sale 1981 , 
Jones 1988). Furthermore, the association of fishes with particular characteristics of the substratum can occur at several different stages of the lifespan. Many species select and settle into distinct habitats as larvae (Booth \& Beretta 1994. Tolimieri 1995), while post-settlement movements in juvenile and adult fishes allow habitat choices to be further refined throughout the adult life (McCormick 1995, Lewis 1997).

Given that fishes associate closely with reef substrata that are subject to recurring disturbance events, it is of ecological and managerial interest to ask how reef fishes respond to perturbation of their habitat. Which taxa are sensitive to disturbance? Are responses rapid, or are there significant time lags between disturbance and response? Do populations respond more through variations in recruitment, post-settlement relocation, or post-settlement mortality? At present, it is difficult to answer these questions because of a lack of rigorous experimentation in this area. There have been studies of the responses of fishes to disturbance by cyclones (Kaufman 1983, Lassig 1983), Acanthaster planci (Williams 1986, Sano et al. 1987), terrigenous nutrlents (Chabanet et al. 1995), and coral mining (Dawson Shepard et al. 1992). However, these 'natural experiments' give researchers little control over experimental conditions, which means that potential disturbance effects may be confounded by natural patterns of temporal and spatial variability, or undetectable because of low statistical power.

This study describes the results of a field experiment based on the 'beyond $\mathrm{BACI}^{\prime}$ (before, after, control, impact) sampling design (Underwood 1992), which examined the responses of fish communities on isolated lagoonal bommies to coral disturbance. This paper deals with the major community-level responses (i.e. changes in community composition, total numbers, and species richness in prominent ecological categories and taxonomic groups); later papers will examine species-specific responses in more detail. Ideally, a BACI experiment should be carried out at a series of study sites with a high degree of similarity, so that tests for disturbance effects are not weakened by spatial variability between sites (Hurlbert 1984, Underwood 1992). The lagoons of many mid-shelf reefs of the Great Barrier Reef complex (Australia) have isolated coral outcrops or 'bommies' which fulfil this criterion. With care, a set of bommies can be chosen that are similar in size, depth, degree of isolation, and fish and coral community composition. Furthermore, visual censuses of fish communities on bommies (108 to $267 \mathrm{~m}^{2}$ ) have higher precision and accuracy than visual censuses of communities on similar areas of contiguous reef, because the fishes do not move in and out of the sampling unit during the census (author's unpubl. data). These 2 characteristics mean that lagoonal bom- mies provide the ideal habitat system in which to conduct a field disturbance experiment.

\section{MATERIALS AND METHODS}

Study location. The study location is $52 \mathrm{~km}$ off the northeast coast of Australia at Little Trunk Reef $\left(18^{\circ} 19^{\prime}\right.$ S, $146^{\circ} 45^{\prime} \mathrm{E}$ ), which forms part of the Great Barrier Reef. Little Trunk Reef is elliptical $(\sim 8 \times 3 \mathrm{~km})$ with the major axis orientated northeast to southwest. Ten bommies located in an open sandy zone at the western margin of the reef flat were used in the experiment. These bommies were selected from the hundreds in the lagoon because they were similar in size, benthic structure, and degree of isolation. They were all surrounded by at least $20 \mathrm{~m}$ of open sand (typically 40 to $50 \mathrm{~m}$ ), were at least $100 \mathrm{~m}$ from each other (typically 200 to $500 \mathrm{~m}$ ), and were in $3 \mathrm{~m}$ of water at low tide. It is unlikely that fishes ever moved directly between any two of them, so in this sense, they are independent replicates. Each bommie consisted of a mound of consolidated substratum approximately $3 \mathrm{~m}$ high and 5 to $10 \mathrm{~m}$ wide, and before the disturbance treatment, live coral colonies covered 29 to $91 \%$ of the surface area of the mounds. A zone of dead coral rubble and isolated live coral colonies surrounded the mounds to a distance of 2 to $5 \mathrm{~m}$. Total planar area of the bommies including the rubble zones varied from 108 to $267 \mathrm{~m}^{2}$. The climate in the study area is typical of tropical regions in the southern hemisphere, with hot wet conditions between October and February, and cool dry conditions between March and September. In this paper, the term 'summer' refers to the October to February period.

The 10 bommies were divided into 2 classes on the basis of fish sampling frequency. Six bommies (labelled A to F) were censused most frequently and are referred to as core bommies, while 4 bommies (labelled $\mathrm{G}$ to J) were censused less frequently and are referred to as non-core bommies. On a given sample occasion, all bommies scheduled for sampling were censused within a $4 \mathrm{~d}$ period between 08:30 and 16:00 h. The sampling program extended over $25 \mathrm{mo}$ and encompassed 2 larval recruitment periods (October to February). During the sampling program, fishes on the core bommies were censused approximately every $30 \mathrm{~d}$ between October and February, and every $60 \mathrm{~d}$ between March and September. Fishes on the non-core bommies were censused 4 times in the 12 mo pre-disturbance phase of the study, and then at the same frequency as the core bommies in the 13 mo postdisturbance phase.

Fish community sampling. All fish censuses were conducted by the author while using SCUBA. Under- 
water visibility always exceeded $15 \mathrm{~m}$, and the census of an individual bommie took from 55 to $70 \mathrm{~min}$ to complete. Species from the following families were counted at each bommie at each census time: Centriscidae, Serranidae, Apogonidae, Lutjanidae, Caesionidae, Nemipteridae, Mullidae, Chaetodontidae, Pomacanthidae, Pomacentridae, Sphyraenidae, Labridae, Scaridae, Blennidae (genus Plagiotremis only), Acanthuridae, Siganidae, Balistidae, Monocanthidae, Ostracidae, Tetraodontidae, and Diodontidae. This selection was made to include fishes with favourable attributes for visual sampling (i.e. moderate to large size, non-cryptic appearance or behaviour). Species were identified on the basis of visual appearance after comparison of video footage taken during the study with photographic references (Randall et al. 1990, Kuiter 1992).

A list of 150 frequently sighted species was printed onto waterproof paper and used to record community composition. A single estimate of abundance was made for each species on the list, and abundance was also estimated for any rare species that were not on the list. For the majority of species that formed aggregations or inhabited distinct zones, I counted the number of fishes in the aggregation or habitat zone respectively. For dispersed species, I censused fish while swimming a zigzag course up the longest axis of the bommie.

Within each census, species were partitioned into recruits and older post-recruit fishes. Recruits were generally considered to be those fishes smaller than $20 \mathrm{~mm}$ standard length, but different maximum size limits were set for the following families; Serranidae 25 to $30 \mathrm{~mm}$. Apogonidae 10 to $15 \mathrm{~mm}$. Chaetodontidae 15 to $20 \mathrm{~mm}$, Labridae $15 \mathrm{~mm}$, Scaridae $15 \mathrm{~mm}$, Acanthuridae 25 to $30 \mathrm{~mm}$. The recruits of the Labridae Cheilinus chlorurus, Coris schroderi, Halichoeres melanurus, $H$. trimaculatus, and Thalassoma Iunare could not be accurately counted, as they were shy and cryptically coloured.

Ecological categories of fishes. In order to investigate whether the coral disturbance affected groups of fishes with similar ecological requirements, the species-level data were aggregated into a matrix of 8 ecological categories, defined by feeding locations and spatial organisation of the fishes on the bommies. These categories were defined on the basis of several hundred hours of visual observations made while censusing the communities over the 25 mo sampling period. The categories were:

A. Small territory algal turf feeders: Species which feed primarily on algae within a small defended territory (usually $<10 \mathrm{~m}^{2}$ ). There were 2 recognisable subcategories.

1. Territorial algal turf farmers. Species which, as adults, defend a small territory and maintain an algal farm that is recognisably different from the algae outside the territory. All species in this category were from the Family Pomacentridae (e.g. Stegastes apicalis, Dischistodus melanotus).

2. Territorial algal turf grazers. Species which defend a small territory and crop the multi-specific algal turf within it, but do not generally develop distinct algal farms. All species in this category were from the Family Pomacentridae (e.g. Pomacentrus adelus, $P$. chrysurus).

B. Large territory substratum feeders: Species which feed primarily from the substratum within a large territory that encompasses the whole bommie area. There were 2 recognisable sub-categories.

3. Large herbivores. Species which feed primarily on plant material and/or detritus; these were typically from the Families Acanthuridae, Scaridae, and Siganidae (e.g. Acanthurus blochil, Scarus rivulatus, Siganus doliatus).

4. Invertebrate feeders. Species which feed primarily on invertebrates; these were typically from the Families Balistidae, Chaetodontidae, Labridae, and Mullidae (e.g. Rhinecanthus aculeatus, Chaetodon rainfordi, Coris schroderi, Parupeneus multifasciatus).

C. Water column feeders: Species which aggregate in schools or aggregate over particular zones of the bommies and feed primarily in the water column. There were 3 recognisable sub-categories.

5. Water column feeders. Species which feed primarily on material taken from the water column; these were typically from the Families Caesionidae and Pomacentridae (e.g. Caesio cuning, Chromis viridis).

6. Water column/substratum feeders. Species which feed primarily from the water column at times of high current movement, and from the substratum at other times; these were all from the Family Pomacentridae (e.g. Chrysiptera rollandi, Pomacentrus amboinensis).

7. Nocturnal feeders. Species which feed primarily on material taken from the water column at night. All species in this category were from the Family Apogonidae (e.g Apogon notatus, Cheilodipterus quinquelineatus).

D. Piscivores: Species which feed primarily on other fishes. There was 1 recognised category

8. Site attached piscivores. Species which feed primarily on other fishes and remain on the bommies while censuses are taking place; these were typically from the Families Lutjanidae and Serranidae (e.g. Lutjanus fulviflamma, Cephalopholis cyanostigma).

Coral sampling. The coral community on each bommie was quantified in terms of the total coral surface 
area in each of a series of categories defined by colony morphology. The disturbance treatment produced living coral rubble which persisted for some time, and this was considered as a separate morphological category. The categories were as follows:

1. Compact arborescent corals: bushy colonies with many short anastomosing branches (e.g. Pocillopora damicornis, Acropora millepora, A. secale).

2. Open arborescent corals: colonies consisting of long, tree-like branches or 'staghorns' (e.g. Acropora nobilis, A. formosa).

3. Encrusting corals: colonies in a flat sheet that adheres to the substratum (e.g. Montipora spp., Echinopora spp.).

4. Tabular corals: colonies that form horizontal tables (e.g. Acropora cytherea, A. hyacinthus).

5. Massive corals: unbranched colonies with a rounded form (e.g Porites luted, Favia spp.).

6. Soft corals: colonies lacking a hard skeleton (e.g. Sarcophyton spp.).

7. Live rubble: Broken pieces of living coral lying on the substratum, produced as a result of the disturbance treatment.

The coral communities on each bommie were sampled with visual censuses and video mapping at regular intervals throughout the study. Data from both techniques were used to quantify the total surface area of each morphological category at the impacted bommies on each of the following dates: March 1993, June 1994, October 1994, January 1995, and June 1995. In the visual censuses, measuring tapes were used to divide the bommie into a series of parallel lanes approximately $1 \mathrm{~m}$ wide. The morphological category and size (to the nearest $20 \mathrm{~cm}$ ) of each colony was then recorded while swimming along each lane. For the video mapping technique, 4 permanent stakes were used to delimit the corners of a square grid which covered the bommie. The grid divided the bommie into parallel lanes $1 \mathrm{~m}$ wide, and the substratum in each lane was filmed with a Sony Hi-8 video camera in an underwater housing. I adjusted my height above the substratum so that the $1 \mathrm{~m}$ wide lane filled the field of view of the camera. The video tape was later played back on a large television screen, and data obtained directly from the video footage. I paused the tape at each coral colony, recorded its morphological category, and measured its size on the screen with a ruler. Given that the total width of the screen was equivalent to the $1 \mathrm{~m}$ wide lane, a simple correction factor was used to convert the screen size of each colony to its actual size. Comparing visual censuses and video maps taken a few days apart showed that the techniques produced almost identical results in terms of total area of each morphological category.
Corals were disturbed in July 1994, after 12 mo of monitoring. Bommies were selected for disturbance such that control and impacted bommies were evenly distributed down the length of the lagoon to avoid confounding the disturbance treatment with spatial position. At the bommies designated for disturbance 13 core and 2 non-core bommies), a mallet was used to break the corals with arborescent and tubular morphologies into small pieces, which were left where they fell. Massive, encrusting, and soft corals were not disturbed.

In the 'Results', data on the coral community are presented as percentage cover of living coral, and cover of each morphological category. The majority of corals were attached to the raised substratum in the central part of each bommie, with few corals found in the perimeter rubble zones. However, rubble zone area varied considerably between bommies, which would confound values of percentage coral cover if total bommie area were used in the calculations. Therefore, I calculated percentage coral cover by dividing coral area by bommie area excluding the area of the rubble zone.

Data analyses. Principal Component Ordinations (PCO) were used to examine the spatial and temporal patterns in fish community structure, in terms of both post-recruit and recruit abundance. A subset of 64 relatively widespread species (from a total pool of 154 species) was selected for the analyses of post-recruit community structure, so as to avoid species whose abundance vectors contained many zeros. Data were converted to $z$-scores (Zar 1984) to standardise for differences in abundance among species; this avoids the problem of the analyses being dominated by the patterns of abundance of a few very common species. The first analysis showed distinct spatial variation in community structure, so to examine temporal variability independent of spatial variability, bommie effects were removed by subtracting the bommie-specific means from each species-specific vector of abundance, and the PCO was repeated.

Spatial and temporal patterns in larval recruitment across the communities were also examined with PCO. Fishes in the recruit size class were observed for 113 of the 154 species in the total pool. The total number of recruits to each bommie in the first (June 1993 to June 1994) and second (July 1994 to July 1995) year of the study was calculated for each species that received recruits. 38 common species were selected from this matrix for PCO, so as to avoid species whose abundance vectors contained many zeros. These data were also transformed to $z$-scores prior to analysis.

Linear Mixed Effects (LME) models were used to test for statistically significant disturbance effects in univariate responses (i.e. total abundance of fishes, total species richness, and abundance and species richness 
within individual families and ecological categories). In the context of repeated measures data arising from a BACI disturbance experiment, LME models offer a useful alternative to traditional univariate or multivariate repeated-measures ANOVA models (e.g. Green 1993), because they accommodate unbalanced data, data collected at different times, and offer the possibility of modelling covariance structures (see Laird \& Ware 1982, Jennrich \& Schluchter 1986, Lindstrom \& Bates 1990). LME models use restricted maximum likelihood iteration to estimate the parameters of a linear expectation function containing both fixed effects (i.e. the disturbance treatment) and random effects (i.e. the effect of time on the individual responses from each bommie). Output is in the form of approximate $z$-ratios or normal deviates, which allows a statistical test of the hypothesis that a given fixed parameter is significantly different from zero. In this case, the basic LME model contained fixed parameters for treatment (control vs impact) effects, temporal effects (before vs after disturbance), and 'treatment $\times$ before/after' interaction effects. The $z$-ratio for the interaction effect is of primary interest, because it can be used to test the hypothesis that the temporal profiles of the impacted bommies diverged from those of the control bommies after the coral disturbance.

Preliminary analyses of the data set revealed that many variables had a component of seasonal variability due to the summer influx of larval recruits, and significant serial correlations between censuses. Consequently, for each variable, a stepwise procedure was used to evaluate whether parameters for these factors should be included in the LME model. In the first step, the basic model was compared to a model containing the same parameters plus a seasonal parameter (incorporated as a sine/cosine function with a period of 1 yr). The $\log$-likelihood ratio statistic was used to test whether there was a significant difference (at $\alpha=0.05$ ) in the fit of the 2 models; if there was, the seasonally adjusted model was retained. In the second step, the seasonally adjusted model without correction for serial correlation (i.e. the model was specified with a uniform within-bommie covariance structure) was compared to a seasonally adjusted model with serial correlation incorporated as a first-order autoregressive (AR1) covariance structure. The log-likelihood ratio statistic was again used to test whether there was a significant difference in the fit of the 2 models; if there was, the model with the AR1 covariance structure was retained. This provides a more conservative estimate of the 'treatment $\times$ before/after' fixed effect, as the $z$-ratios are automatically corrected for the serial correlations in the data. The 'Results' section indicates whether the LME models for particular variables were adjusted for seasonality, serial correlations, or both. Data analyses were performed using S-Plus for Windows software. The LME functions were written by J. C. Pinheiro at Bell Laboratories, Murray Hill, NJ, USA, and D. M. Bates at the University of Wisconsin-Madison, USA, and can be obtained from these authors.

\section{RESULTS}

\section{Coral disturbance}

All bommies had moderate to high coral cover (29 to $91 \%$ ) before the disturbance treatment; however there was considerable variation between bommies in percentage coral cover (Table 1). Corals with compact arborescent, open arborescent, and tabular morphologies were the most common, and these 3 groups also showed the fastest increases in percentage cover (Fig. 1). Soft corals were the only category to show a significant natural decline during the experiment, and this was consistent across all bommies.

Table 1. Percentage live coral cover on the 10 bommies immediately prior to the disturbance and over the post-disturbance period. Coral on the impacted bommies was disturbed in July 1994. Corals on the control bommies were not censused in October 1994 and January 1995

\begin{tabular}{|c|c|c|c|c|c|c|}
\hline Treatment & Bommie & $\begin{array}{c}\text { June } 1994 \\
\text { (pre-disturbance) }\end{array}$ & October 1994 & Januāry 1995 & June 1995 & $\begin{array}{l}\text { Change from June } \\
1994 \text { to June } 1995\end{array}$ \\
\hline Impacted & $B$ & 90 & 39 & 27 & 27 & -63 \\
\hline Impacted & D & 91 & 41 & 33 & 42 & -49 \\
\hline Impacted & $F$ & 44 & 32 & 27 & 29 & -15 \\
\hline Impacted & $\mathrm{G}$ & 77 & 30 & 37 & 34 & -43 \\
\hline Impacted & I & 29 & 15 & 16 & 12 & -17 \\
\hline Control & A & 64 & & & 70 & 6 \\
\hline Control & $\mathrm{C}$ & 75 & & & 80 & 5 \\
\hline Control & $\mathrm{E}$ & 30 & & & 36 & 6 \\
\hline Control & $\mathrm{H}$ & 37 & & & 41 & 4 \\
\hline Control & J & 66 & & & 56 & -10 \\
\hline
\end{tabular}




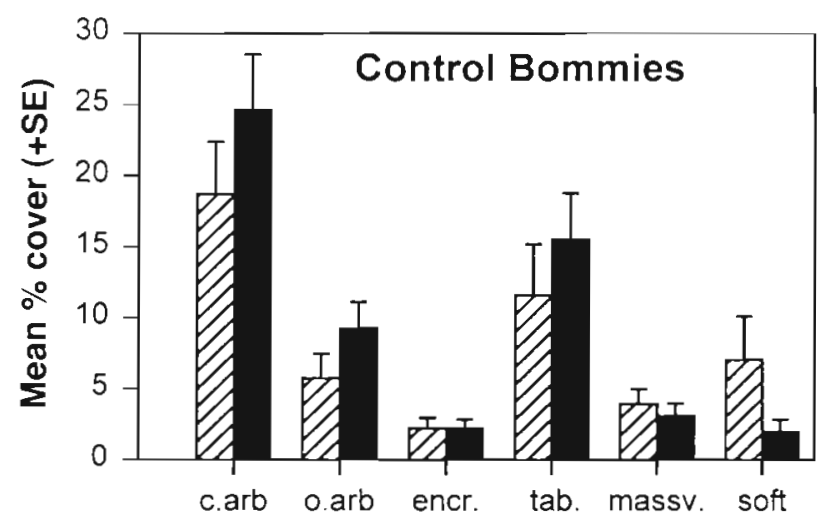

Coral Morphological Category

Fig. 1. Mean percentage cover of different morphological groups of corals (c.arb: compact arborescent; o.arb: open arborescent; encr: encrusting; tab.: tabular; massv.: massive; and soft) at the undisturbed control bommies in June 1993 (hatched bars) and June 1995 (solid bars)

The disturbance treatment substantially altered the physical appearance and the fine-scale $(1 \mathrm{~m})$ spatial heterogeneity of the impacted bommies, and initially produced large amounts of living coral rubble. The compact arborescent, open arborescent, and tabular corals showed large reductions in area (Fig. 2). Coral fragment mortality was offset by regrowth of the surviving colonies, so that total cover of living coral remained relatively stable on the impacted bommies in the post-disturbance period (Fig. 2, Table 1). Recovery of surviving coral fragments was rapid, with pieces from the same colony fusing after 1 mo and establishing new margins of active growth after 2 mo. Most surviving colonies had reestablished their specific morphologies after 6 mo, so the coral communities at the impacted bommies consisted of numerous small colonies and very little live rubble in the last 6 mo of the sampling program (Fig. 2). Regrowth of up to $200 \mathrm{~mm}$ had occurred in some tabular and open arborescent Acropora sp. by the end of the study. Percentage coral cover at the impacted bommies had fallen on average by $34 \%$ at the end of the study, and bommies that had high coral cover showed the greatest reductions, losing more than half their living coral (Table 1). Coral cover increased by about $5 \%$ in the same period at the control bommies, although bommie $\mathrm{J}$ showed a reduction in cover because several large tabular corals died from disease.

\section{Fish responses - community level}

Differences in fish community structure among bommies were the largest source of variability in post-recruit abundance. The first principal component accounted for $17.3 \%$ of the variability in the dataset and describes a north-south gradient in community composition, with bommies on the left of the ordination located in the northern part of the lagoon (Fig. 3A). There were distinct spatial patterns in the abundance of many species, and these patterns were maintained throughout the study at both control and impacted bommies, as evidenced by the tight grouping of bommie-specific samples in the ordination. This result suggests that disturbance effects in these fish communities are much smaller than differences in abundance among bommies. In the ordination following removal of bommie effects, there was still no distinct separation of 'impact-after' samples from 'impact-before', 'control-before', or 'control-after' samples (Fig. 3B). 'Impact-after' samples were relatively distinct from 'impact-before' samples, but the control bommies also showed a distinct 'before/after' difference, implying that all bommies showed some temporal changes in community structure.

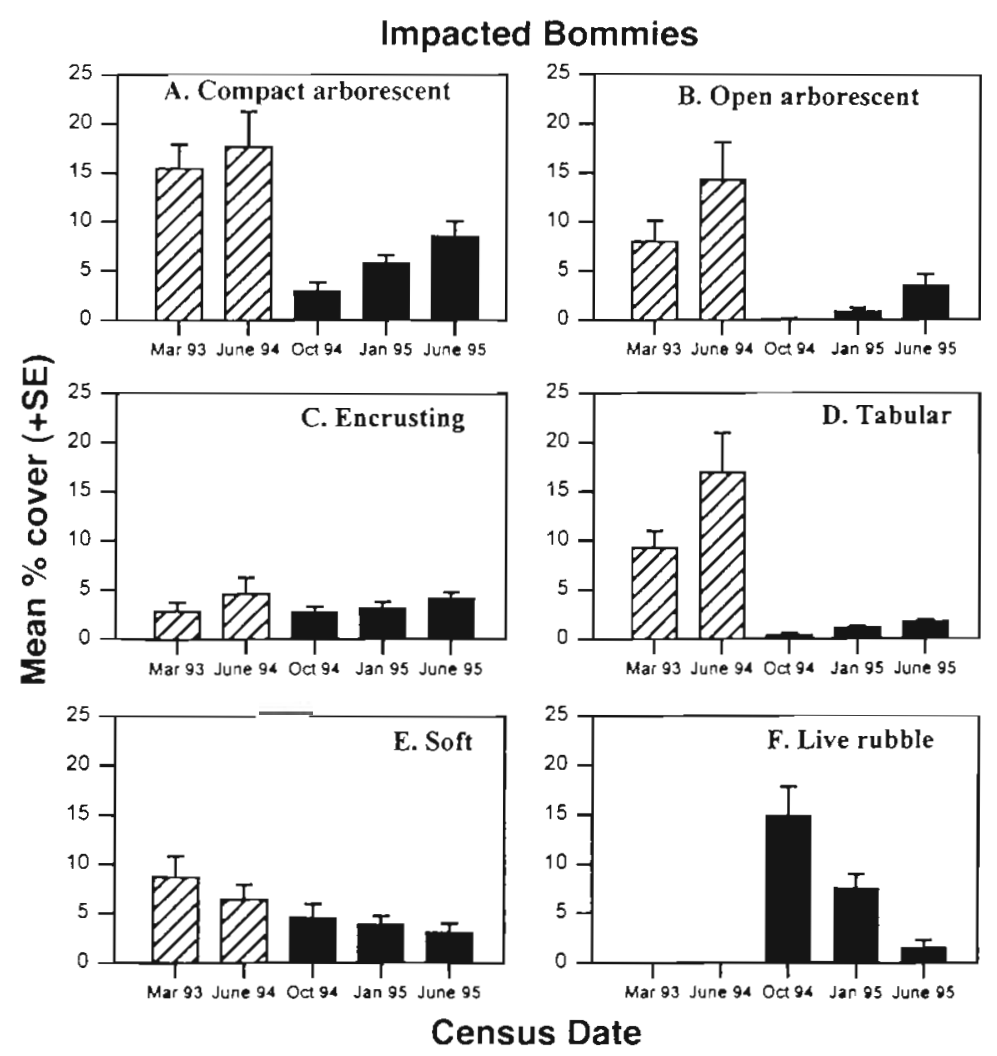

Fig. 2. Mean percentage cover of 6 morphological groups of corals (A-F) at the impacted bommies. Hatched and solid bars indicate census occasions before and after the disturbance treatment respectively. Massive corals were not affected by the disturbance and are not shown here 


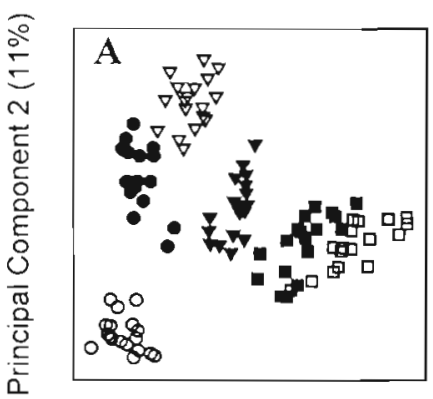

Principal Component $1(17 \%)$

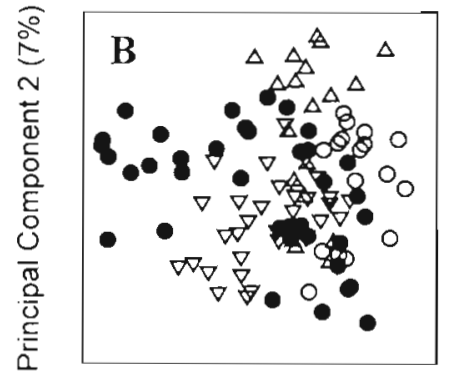

Principal Component $1(11 \%)$

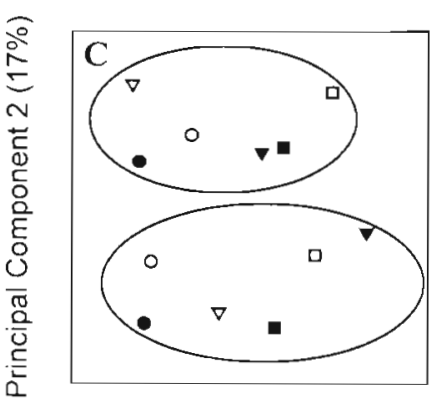

Principal Component $1(17 \%)$

Fig. 3. (A) Principal components ordination (PCO) of a matrix containing post-recruit abundances of 64 fish species at the 6 core

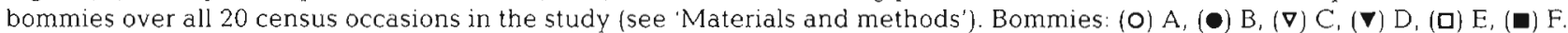
Each symbol corresponds to a single census; open symbols: control bommies; filled symbols: impact bommies. (B) PCO of the above matrix, with bommie effects removed. Triangles: samples from control bommies before $(\Delta)$ and after $(\nabla)$ the disturbance; circles: samples from impacted bommies before $(0)$ and after $(\bullet)$ the disturbance. (C) PCO of a matrix containing the total number of recruits of 38 fish species over the first and second summers of the study. Symbols as in (A). Upper ellipse encompasses samples from all bommies in the first summer (October 1993 to February 1994); lower ellipse encompasses samples from all bommies in the second summer (October 1994 to February 1995)

There was, however, a difference in the direction of these changes between treatments; the impacted bommies varied along the axis of the first principal component, while the control bommies varied along the axis of the second principal component. It is impossible to state whether this difference in the direction of change was due to disturbance effects or natural temporal variability in community structure, because there was considerable overlap in the 'after' samples from both control and impacted bommies. Overall, the data suggest 2 things: (1) the coral disturbance had no significant effect on the relative abundance of species within these fish communities, and (2) the pre-existing differences in fish community structure between bommies were not due to differences in coral cover.

The coral disturbance had no effect on the community-level recruitment of fishes, as there was no tendency for samples from the impacted bommies to group separately from the control bommies in the postdisturbance period (Fig. 3C). However, there were important differences in the spatio-temporal patterns of community-wide recruitment compared to the underlying patterns of post-recruit relative abundance. In the post-recruit ordination (Fig. 3A), both the first and second principal components describe spatial variability in community structure between bommies; temporal variation is small in comparison to spatial variation. In the recruit ordination, temporal variability in the relative abundance of recruits is of a similar magnitude to the spatial variability among bommies. The first principal component accounts for $\sim 17 \%$ of the variability in the dataset (Fig. $3 \mathrm{C}$ ), and it describes a north-south lagoonal gradient similar to that seen in the adult ordination (Fig. 3A). The second principal component also accounts for $-17 \%$ of the variability, and it separates the samples taken in the first year from those in the second. The direction of the lagoonal gradient is consistent in both years, although there is some inter-annual change in the relative position of samples from each bommie.

Superimposing the species vectors on the ordination (not illustrated here) showed that there were 3 groups of species which were responsible for the position of the samples in the ordination space (Fig. $3 \mathrm{C}$ ). The first group consisted of species which showed distinct patterns of spatial variability in recruitment that were maintained in both years (e.g. Pomacentrus adelus had consistently higher recruitment on the southern bommies, while $P$. coelestis had consistently higher recruitment on the northern bommies). This group of species was responsible for maintaining the north-south lagoonal gradient. The second group of species showed higher recruitment in the first year at all bommies (e.g. Pomacentrus nagasakiensis, Chaetodon rainfordi), while the third group showed higher recruitment in the second year at all bommies (e.g. Pomacentrus amboinensis, Dischistodus melanotus). These latter 2 groups were responsible for the clear inter-annual separation of samples that is described by the second principal component of the ordination (Fig. 3C).

\section{Fish responses - total abundance and species richness}

In the 3 to 4 mo after the disturbance, the mean total abundance of fishes (recruits and post-recruits) at the impacted bommies declined by 10 to $20 \%$ relative to the control bommies (seasonally adjusted LME model 
with AR1 serial correlation, $z=-1.87, p=0.031$; Fig. 4A). Despite this decline, the disturbance did not affect the overall temporal dynamics of total abundance, and a similar sequence of seasonal changes occurred in both years of the study. Total abundance was high and relatively stable through winter, but declined sharply in the spring months preceding the larval recruitment period. The influx of recruits increased total abundance over summer, and maxima usually occurred during the February or April censuses. The difference in total abundance between control and impacted bommies was largest in January $1995(\sim 40 \%)$, because greater recruitment had occurred at the control bommies in the preceding 2 mo. Recruitment occurred at the impacted bommies between the January and February censuses, and at the end of the study in July 1995, total abundance was $-20 \%$ lower at the impacted bommies. Control bommies received more recruits than impacted bommies in both summers (2-way ANOVA, $F=5.44, p=0.048$; Fig. 5A), and there was greater recruitment to all bommies in the second summer (2-way ANOVA, $F=5.96$, $\mathrm{p}=0.041$ ); however there was no significant treatment $x$ before/after interaction in terms of total recruitment (2-way ANOVA, $F=0.37, \mathrm{p}=0.56$ ).
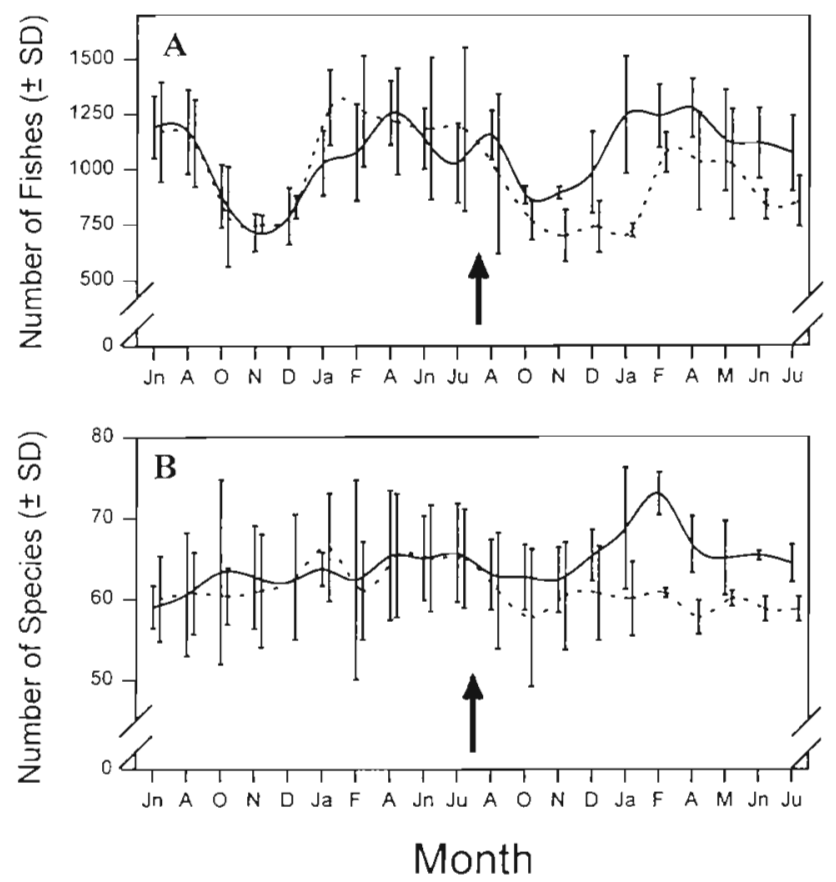

Fig. 4. (A) Mean total number of fishes at the control (solid line) and impacted (dashed line) bommies. The $x$-axis refers to the month in which a given census was taken; the sampling program began in June 1993 and extended to July 1995, and the arrow marks the time of the coral disturbance. (B) Mean species richness at the control (solid line) and impacted (dashed line) bommies
There was a significant decline in species richness at the impacted bommies relative to the control bommies after the coral disturbance (seasonally adjusted LME model with AR1 serial correlation, $z=-2.75, \mathrm{p}=0.003$ ), and the effect size as measured by the $z$-ratio was the highest of any of the variables tested. Species richness at the impacted bommies did not increase at any time after the disturbance, whereas there was a clear increase at the control bommies in the second summer (Fig. 4B). At the end of the study, species richness was $-10 \%$ higher at the control bommies. The species composition of all bommies was constantly changing due to recruitment, migration, and predation, yet species richness at each bommie was reasonably consistent through time. Hence, it appears that the coral disturbance affected each bommie's overall species carrying capacity, rather than causing extinctions of particular species.

There was no evidence for disturbance effects in terms of recruit species richness (2-way ANOVA, treatment $\times$ before/after interaction, $F=0.01, p=0.9_{i}$ Fig. 5B). A similar number of species received recruits at control and impacted bommies, and all bommies received more species in the second summer (2-way ANOVA, $F=7.56, p=0.02$; Fig. 5B).
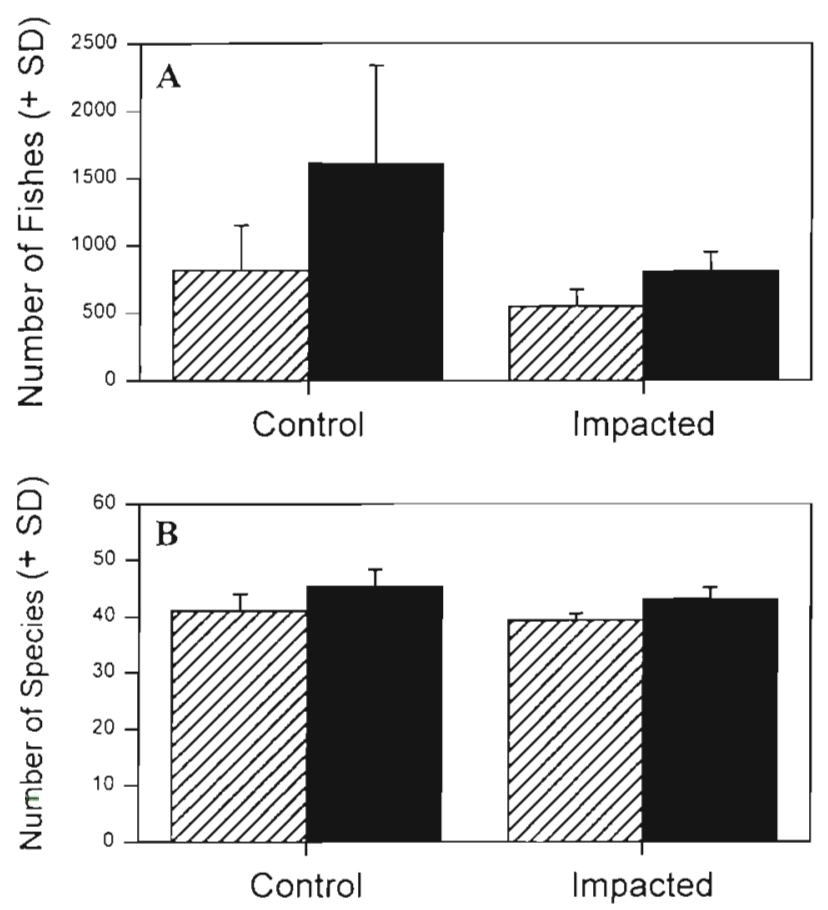

Fig. 5. (A) Mean total number of recruits at the control and impacted bommies. Hatched bars indicate the 1993-1994 summer penod (pre-disturbance), and solid bars indicate the 1994-1995 summer period (post-disturbance). (B) Mean species richness of recruits at the control and impacted bommies. Bars as in (A) 


\section{Fish responses - family level}

LME models were used to test for effects of the coral disturbance on total numbers of fishes and species richness in 6 major taxonomic families: the Serranidae, Pomacentridae, Chaetodontidae, Apogonidae, Labridae, and Scaridae (Table 2). The Chaetodontidae were the only family to show a significant reduction in abundance, with total numbers at the impacted bommies declining gradually after the disturbance to be $\sim 50 \%$ lower than the control bommies by the end of the study (Fig. 6A).

There were significant treatment $\times$ before/after interactions in species richness for 2 families, the Apogonidae and the Scaridae (Table 2). In the Apogonidae, species richness declined at the impacted bommies by 1 to 3 species in the 4 mo following the coral disturbance, then increased again over the second summer (Fig. 7A). There was no difference in the species richness of this family between impacted and control bommies by the end of the study. Species richness in the Scaridae was generally higher on the impacted bommies than the control bommies in the pre-disturbance period (Fig. 7B), but declined to a similar level in the 3 to 4 mo following the disturbance and remained there throughout to the end of the study.

\section{Fish responses - ecological categories}

LME models were used to test for effects of the coral disturbance on total numbers of fishes and species richness in the 8 ecological categories (Table 3 ). The water column/substratum feeders, which are all from the family Pomacentridae, were the only category to show a significant reduction in abundance at the impacted bommies (Fig. 6B). There was little difference in abundance until the summer following the dis-

Table 2. Tests for effects of coral disturbance on the numbers of fishes and species richness in each of 6 major taxonomic families. Disturbance effects were estimated by $z$-ratios for the 'treatment $x$ before/after' interaction term in a Linear Mixed Effects model. "Statistically significant $z$-ratios (for $\alpha=0.05$ )

\begin{tabular}{|lcccc|}
\hline \multirow{2}{*}{ Family } & \multicolumn{2}{c}{ Abundance } & \multicolumn{2}{c}{ Species richness } \\
& $z$-ratio & $p$-value & $z$-ratio & p-value \\
\hline Chaetodontidae & $-1.68^{\mathrm{a}, \mathrm{b}}$ & $0.046^{\circ}$ & $-1.49^{\mathrm{b}}$ & 0.068 \\
Apogonidae & $-1.49^{\mathrm{a}, \mathrm{b}}$ & 0.068 & $-2.11^{\mathrm{a}, \mathrm{b}}$ & $0.017^{\circ}$ \\
Pomacentridae & $-1.29^{\mathrm{a}, \mathrm{b}}$ & 0.098 & $+0.11^{\mathrm{a}, \mathrm{b}}$ & 0.456 \\
Labridae & $+1.25^{\mathrm{a}}$ & 0.106 & $-1.23^{\mathrm{a}, \mathrm{b}}$ & 0.109 \\
Serranidae & $+1.04^{\mathrm{a}, \mathrm{b}}$ & 0.149 & $+0.73^{\mathrm{b}}$ & 0.233 \\
Scaridae & $+0.33^{\mathrm{a}}$ & 0.371 & $-1.70^{\mathrm{b}}$ & $0.045^{\circ}$ \\
& \\
a Models that included terms for seasonal variability (see 'Materials \& methods') \\
'Models that included terms for serial correlation (see 'Materials \& methods')
\end{tabular}

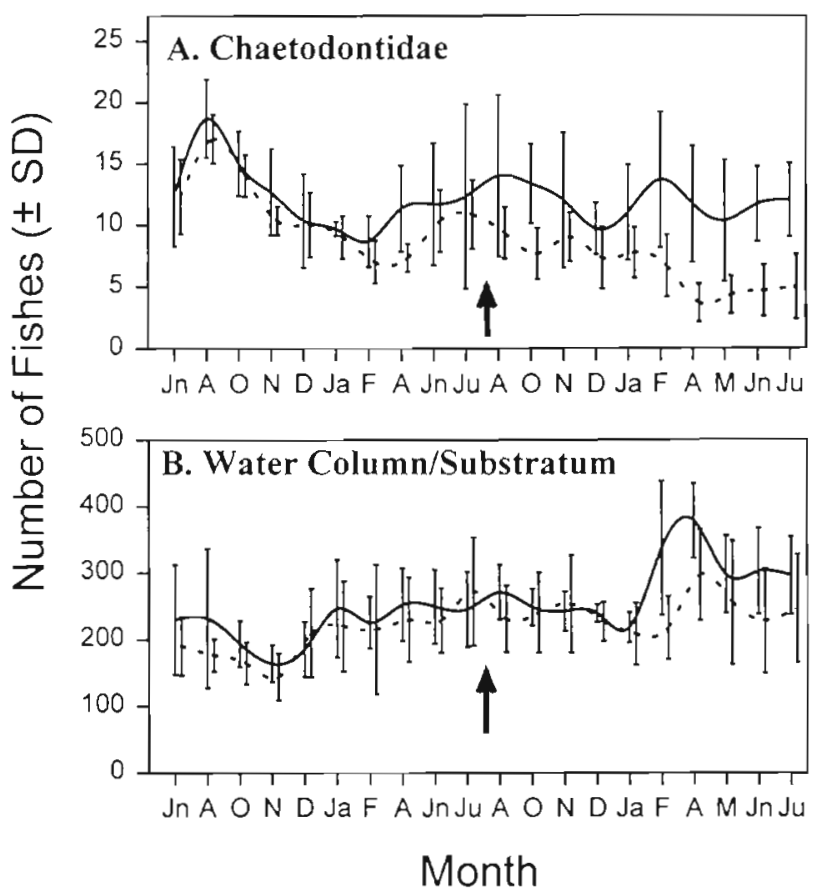

Fig. 6. (A) Mean number of fishes in the family Chaetodontidae at the control (solid line) and impacted (dashed line) bommies. The $x$-axis refers to the month in which a given census was taken; the sampling program began in June 1993 and extended to July 1995, and the arrow marks the time of the coral disturbance. (B) Mean number of fishes in the water column/substratum feeding ecological category at the control (solid line) and impacted (dashed line) bommies

turbance, when the impacted bommies received only about half as many recruits as the control bommies. This resulted in a smaller increase in adult abundance over this period, and by the end of the study, the abundance of fishes in this ecological category was $-16 \%$ lower at the impacted bommies. The coral disturbance had a positive effect on recruitment in the territorial algal turf farming pomacentrids, with 4 of the 5 disturbed bommies receiving relatively high numbers of recruits in the summer after the disturbance. The higher recruitment had little effect on adult abundance, however, and by the end of the study 6 mo later, there was little difference between control and impacted bommies in terms of the abundance of fishes in this ecological category.

There was a significant decline in the species richness of 1 ecological category of fishes, the invertebrate feeders (Table 3). Species richness on the impacted bommies began to 
decline within 2 mo of the disturbance, and by the end of the study, the impacted bommies had $\sim 13 \%$ fewer species than the control bommies (Fig $7 \mathrm{C}$ ).

\section{DISCUSSION}

In these fish communities, bommie-specific patterns of relative abundance remained relatively consistent throughout the 25 mo sampling period, despite the coral disturbance treatment and regular seasonal

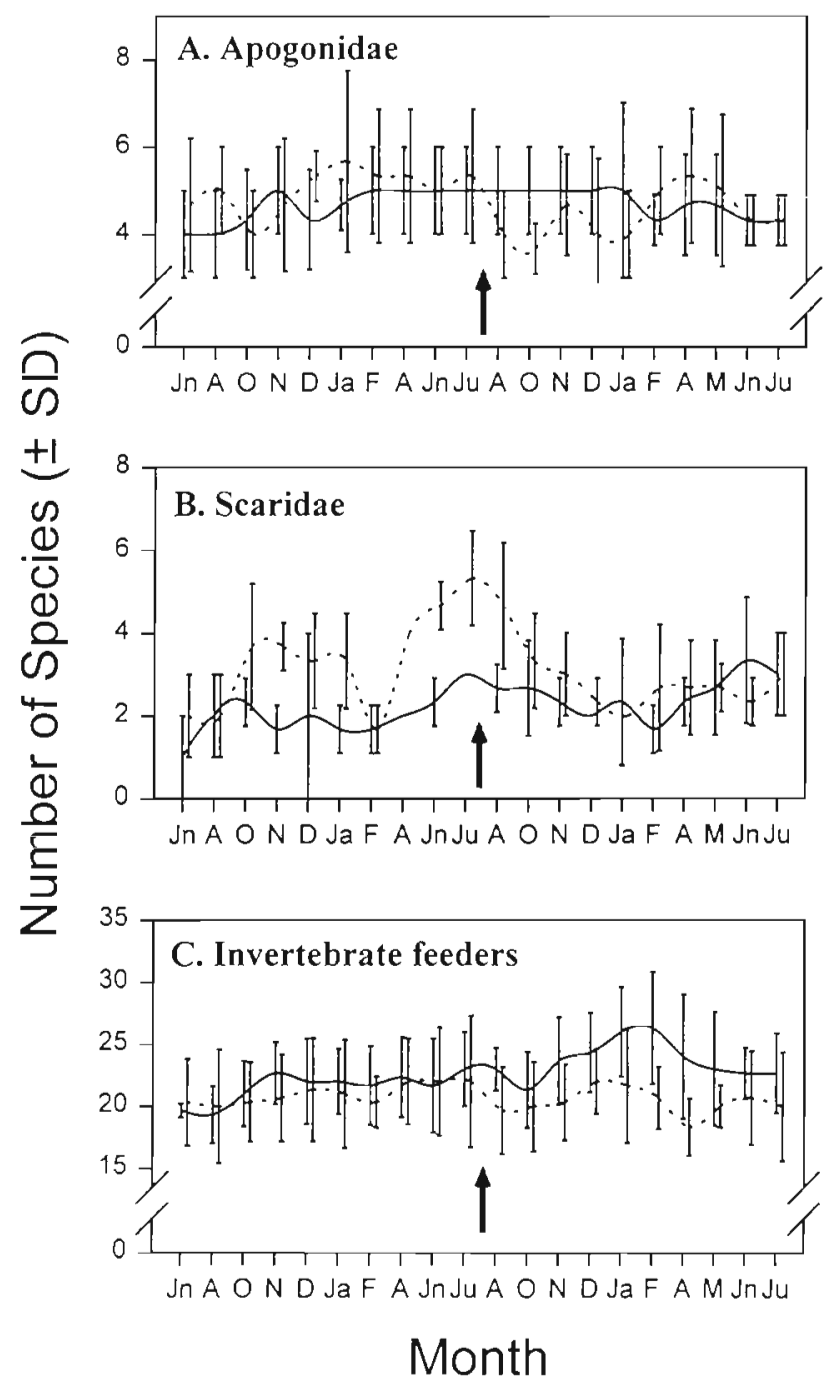

Fig. 7. (A) Mean species richness of the family Apogonidae at the control (solid line) and impacted (dashed line) bommies. The $x$-axis refers to the month in which a given census was taken; the sampling program began in June 1993 and extended to July 1995, and the arrow marks the time of the coral disturbance. (B) Mean species richness of the family Scaridae at the control (solid line) and impacted (dashed line) bommies. (C) Mean species richness of invertebrate feeders at the control (solid line) and impacted (dashed line) bommies dynamics driven by larval recruitment, mortality, and between-bommie movement (Lewis 1997). As a result, multivariate ordinations of the data showed no evidence of disturbance effects (Fig. 3). However, significant declines in total abundance and species richness were detected, and these 2 variables have previously been correlated with spatial variability in coral cover at lagoonal sites in French Polynesia (Bell \& Galzin 1984). The population size of most species was unaffected by the coral disturbance. However, several of the species that showed small relative declines had very high abundances, which caused the drop in total abundance without substantially affecting community structure. These results are unusual because other studies of the effects of disturbance on marine communities, including assemblages of coral reef fishes (Dawson Shepard et al. 1992), have found that multivariate analyses of community structure are usually more sensitive than aggregated univariate measures (see review by Warwick \& Clarke 1991). The data from this study indicate, for reef fishes at least, that disturbances which have no effect on multivariate community structure may still induce changes in aggregate measures such as total abundance and species richness; thus an analytical approach that examines both multivariate and univariate responses is recommended.

Coral cover had no effect on the bommie-specific patterns of relative abundance in these fish communities. This raises the question of which factors were responsible for the maintenance of distinct communities on each bommie over the $2 \mathrm{yr}$ of the study. The most likely explanation is that the underlying shapes and spatial heterogeneity of the hard substrata at each bommie also affected the composition of the fish communities, independent of variations in coral cover. Each bommie had 3 broadly recognisable zones: a central mound of consolidated coral rock that was 2 to $3 \mathrm{~m}$ above the surrounding sand, a spatially heterogenous area of live coral and coral rock that was 0.5 to $1 \mathrm{~m}$ above the sand and surrounded the central mound, and an area of low coral rubble that extended around the periphery of each bommie. The shapes and proportions of each of these zones varied considerably between bommies, and were unaffected by the coral disturbance. At the scale of a single bommie, there were clear associations between these zones and the spatial distributions of both adult and newly settled larval fishes (pers. obs.). In some species (typically substratum feeders), the larvae settled directly into the preferred adult spatial location, while in others (typically water column feeders), the newly settled fishes had a distinct spatial location of their own, and moved into the adult location as they grew larger. Furthermore, there were frequent interchanges of fishes between bommies due to movement (Lewis 1997), and new 
Table 3. Tests for effects of coral disturbance on the numbers of fishes and species richness in each of 8 ecological categories. Disturbance effects were estimated by z-ratios for the 'treatment $x$ before/after' interaction term in a Linear Mixed Effects model. - Statistically significant $z$-ratios (for $\alpha=0.05$ )

\begin{tabular}{|c|c|c|c|c|}
\hline \multirow{2}{*}{$\begin{array}{l}\text { Ecological } \\
\text { category }\end{array}$} & \multicolumn{2}{|c|}{ Abundance } & \multicolumn{2}{|c|}{ Species richness } \\
\hline & $z$-ratio & p-value & $z$-ratio & p-value \\
\hline Water column/substratum feeders & $-1.92^{\mathrm{a}, \mathrm{b}}$ & $0.028^{*}$ & $+0.96^{b}$ & 0.168 \\
\hline Water column feeders & $-1.50^{a b}$ & 0.067 & $-0.53^{a, b}$ & 0.298 \\
\hline Nocturnal feeders & $-1.14^{a . b}$ & 0.127 & $-1.54^{a, b}$ & 0.062 \\
\hline Territorial algal turf farmers & $+0.91^{\mathrm{d} b \mathrm{~b}}$ & 0.184 & $-0.40^{a, b}$ & 0.345 \\
\hline Territorial algal turf grazers & $+0.86^{a_{b} b}$ & 0.195 & $+0.97^{b}$ & 0.166 \\
\hline Site-attached piscivores & $-0.78^{a}$ & 0.248 & $-1.20^{\mathrm{a}, \mathrm{b}}$ & 0.115 \\
\hline Invertebrate feeders & $+0.30^{\mathrm{a}}$ & 0.382 & $-2.46^{\circ}$ & $0.007^{\circ}$ \\
\hline Large herbivores & $-0.016^{\mathrm{a}}$ & 0.492 & $-1.57^{b}$ & 0.058 \\
\hline
\end{tabular}

immigrants would also occupy the same spatial position as con-specifics. These observations suggest that the shape and structure of the substratum at each bommie determined the amount of appropriate habitat that was available to each species to a greater extent than the living coral community.

The consistent spatial differences in communitylevel recruitment (Fig. 3C) indicate that many species were responding to particular substratum characteristics at the time of settlement, and several previous studies have shown that reef fish larvae have the ability to select appropriate settlement locations based on their micro-habitat requirements (Doherty 1983, Booth \& Beretta 1994, Tolimieri 1995). In many other species in this study, the inter-annual variations in total recruitment were much larger than intra-annual spatial variations between bommies, and this resulted in clear differences in community-level recruitment between years. However, these inter-annual differences in recruitment did not cause a corresponding shift in the structure of the adult communities (Fig. 3A). Thus, post-settlement processes (i.e. mortality and movement) must also contribute to the maintenance of distinct patterns of relative abundance at each bommie by stabilising the temporal variability in population size induced by seasonal recruitment pulses. Differences in refuge availability between patch reefs are known to modify patterns of abundance established at settlement, presumably because of differential mortality (Caley 1993, Caley \& St John 1996). Movement between bommies has been documented for many of the species in this study (Lewis 1997), and this would facilitate the process of habitat selection throughout the remainder of the reef-associated phase of the life cycle.

Despite the lack of major community-level responses to the coral disturbance, there were nevertheless detectable changes in the abundance and species rich- ness of several taxa and ecological categories. The Chaetodontidae showed the largest decline in terms of abundance, and the species of this family have previously been put forward as candidates for coral bioindicators, because many are obligate coral feeders (Hourigan et al. 1988). However, the degree to which chaetodont populations are limited by the abundance of live coral is still uncertain. Studies of the correlation between chaetodont abundance and live coral cover have produced conflicting results; in some cases positive correlations were found (Bell \& Galzin 1984, Bouchon-Navaro \& Bouchon 1989, Jones \& Kaly 1996), and in other cases they were not (Bell et al. 1985, Findley \& Findley 1985, Roberts \& Ormond 1987, Fowler 1990, Jones \& Kaly 1996). However, a correlation between resource abundance and consumer numbers does not demonstrate resource limitation; the definitive test is whether a manipulation of resource density produces a concurrent change in abundance (Jones 1991).

Massive reductions in coral cover due to Acanthaster planci outbreaks are known to produce a decline in chaetodont abundance (Bouchon-Navaro et al. 1985, Williams 1986, Sano et al. 1987). This study is the first to demonstrate a link between chaetodont abundance and coral cover in a field disturbance experiment. Although these results indicate that populations of chaetodontids may be resource limited, that does not necessarily make the species of this family good bioindicators; indeed, the changes in coral composition in this study, and those resulting from $A$. planci outbreaks, were so distinct as to make the need for bioindicators superfluous. A good bio-indicator should respond in a predictable way to a wide range of changes in resource quality, and especially to small changes which may be difficult to detect by other means. These properties have not yet been demonstrated for chaetodontids. 
The loss of habitat structure provided by the coral had the greatest effect on the fish communities in this study. Coral cover on the impacted bommies was relatively stable in the post disturbance period, and corals began to recover their specific morphologies after only a few months, yet chaetodontid abundance at the impacted bommies continued to decline through to the end of the study. This suggests these fishes were affected more by the loss of habitat structure than the loss of food, and that adult emigration or mortality were the major factors responsible for the decline. Loss of habitat structure also appears to be responsible for the decline in abundance of fishes in the water column/substratum feeding ecological category. The damselfish Pomacentrus moluccensis was the most abundant species in the study and accounted for the majority of individuals in this ecological category. This species shelters in corals with arborescent morphologies, and its larvae settle directly into these corals. In contrast to the chaetodontid response, the abundance of these damselfish was not affected until the summer following the disturbance, when recruitment was $-50 \%$ lower at the impacted bommies. Thus, it is clear that the responses of populations of reef fishes to coral disturbance depends on taxon-specific life-history traits, and that changes in population size due to emigration, mortality, and recruitment modification are all possible.

Two families (Apogonidae and Scaridae) and 1 ecological category (invertebrate feeders) showed significant declines in species richness after the disturbance, but in each case the absolute number of species involved was relatively small. The decline in the Apogonidae was again related to a loss of habitat structure, as members of this nocturnal family shelter between the branches of live coral during the day. The response of this taxon was quite short-lived, with species richness recovering on the impacted bommies by the end of the study. This is probably related to the frequent between-bommie movements shown by species of this family (Lewis 1997), enabling a rapid initial response to the disturbance and then a gradual recolonisation that paralleled the re-establishment of specific growth morphologies in the damaged coral colonies. The response of the Scaridae is more difficult to explain, as members of this taxon are herbivorous and do not commonly shelter within live coral during the day. Given the large pre-disturbance difference in scarid species richness between control and impacted sites, and the fact that species richness on the impacted sites dropped to that of the control sites twice in the pre-disturbance period (Fig. 7B), the post-disturbance decline may be the result of natural between-bommie variation instead of the coral disturbance. However, Bell \& Galzin (1984) also found that the species rich- ness of the Scaridae was positively correlated with live coral cover in the lagoon of a French Polynesian atoll, so it is possible the decline observed here was related to the coral disturbance. Members of this family do shelter within live coral at night (Randall et al. 1990), so the decline may be related to a reduction in the number or quality of nocturnal shelter sites.

The invertebrate feeders showed a $13 \%$ decline in species richness, and this is significant because the natural temporal variability in both species richness and abundance of this ecological category was very small. Although this category contains some obligate coral feeders (i.e. some Chaetodontidae, and the Labridae Labrichthys unilineatus and Labropsis australis), it does not appear that a food shortage for these taxa was the reason for the decline, as the Family Chaetodontidae showed no reduction in species richness (Table 2). The fact that there was no decline in the total abundance of invertebrate feeders indicates that the decline in species richness was due to the loss of rare rather than common species.

In this study, families or ecological categories which showed disturbance responses in terms of abundance did not show effects in terms of species richness, and vice versa (Tables $2 \& 3$ ), which means that the effects of the coral disturbance varied widely among species within these groups. When 1 or more common species were affected, the result was a decline in abundance with no change in species richness (e.g. the Chaetodontidae), while if 1 or more rare species were affected, the result was a change in species richness with no change in abundance (e.g. the invertebrate feeders). It is debatable whether the change in abundance of a common species after a disturbance is more significant than the local extinction of a rare species; the data from this study suggest that both responses are likely in diverse reef fish communities, and therefore temporal profiles of abundance and species richness should both be assessed for disturbance effects.

The 'beyond BACI' sampling design (Underwood 1992) used in this study is an example of a manipulative experiment (sensu Hurlbert 1984) with a single treatment factor. In such an experiment, replicate sites should be as similar as possible in order to reduce random error and maximise the power of the experiment to detect treatment effects (Huribert 1984, Dutilleul 1993). The 10 bommies I sampled were selected from hundreds of others because they were similar in size, shape, and degree of isolation, yet there were differences between them in terms of substratum characteristics, coral cover, and fish community structure (Table 1, Fig. 3A). This spatial heterogeneity did not preclude the statistical detection of disturbance effects, although it does suggest that additional effects may have been apparent had a larger number of bommies 
been sampled. Clearly, the high species djversity and extreme patchiness of the coral reef environment makes it difficult to achieve similarity among replicates, which weakens the power to resolve disturbance effects in the context of both manipulative experiments and environmental impact assessments. For this reason, ecologists and managers must take extra care to ensure that their coral reef sampling programs are properly designed (see Green 1979, Hurlbert 1984, Andrew \& Mapstone 1987), particularly with respect to adequate replication in time and space.

In summary, physical disturbance to the live coral communities on 5 large bommies reduced coral cover from -66 to $\sim 29 \%$. This affected several aspects of the associated fish communities, including total abundance, species richness, and the abundance and species richness of certain families and ecological groups. However, bommie-specific patterns of relative abundance in the fish communities were largely unaffected by the disturbance. Characteristics of the underlying hard substratum at each bommie appeared to influence recruitment, post-settlement mortality, and between-bommie movement to produce these patterns of relative abundance. The contemporary appearance of the hard substrata on these bommies is the result of prior coral growth, consolidation, and bio-erosion, so the patterns of community structure in these fish communities will be related to the historical rates of these processes, as well as the veneer of living coral. Further studies of fish-habitat associations, together with field experiments which manipulate both the underlying substratum and the abundance of live corals, will be necessary to determine the relative importance of each of these habitat characteristics to reef fishes.

Acknowledgements. This work was funded by grants from James Cook University and the Great Barrier Reef Marine Park Authority. I thank Robert C. Lewis and J. Howard Choat for logistic support, the staff of Orpheus Island Research Station, and the numerous friends who assisted with field work. Multivariate data analyses were performed with the 'Sophie' software for S-Plus, written by Glen De'ath. José Pinheiro provided advice on the use of Linear Mixed Effects models. Julian Caley, Geoff Jones, J. Howard Choat, and 3 anonymous reviewers provided helpful comments which improved earlier versions of the manuscript.

\section{LITERATURE CITED}

Andrew NL, Mapstone BD (1987) Sampling and the description of spatial pattern in marine ecology. Oceanogr Mar Biol Annu Rev 25:39-90

Bell JD, Galzin R (1984) Influence of live coral cover on coral reef fish communities. Mar Ecol Prog Ser 15:265-274

Bell JD, Harmelin-Vivien ML, Galzin R (1985) Large scale spatial variation in abundance of butterflyfishes (Chaetodontidae) on Polynesian reefs. Proc 5th Int Coral Reef Congr 5:421-426
Booth DJ, Beretta GA (1994) Seasonal recruitment, habitat associations and survival of pomacentrid reef fish in the US Virgin Islands. Coral Reefs 13:81-89

Bouchon-Navaro Y, Bouchon C (1989) Correlations between chaetodontid fishes and coral communities of the Gulf of Aqaba (Red Sea). Environ Biol Fishes 25:1-3

Bouchon-Navaro Y, Bouchon C, Harmelin-Vivien N.IL (1985) Impact of coral degradation on a chaetodontid fish assemblage (Moorea, French Polynesia). Proc 5 th Int Coral Reef Congr 5:427-432

Caley MJ (1993) Predation, recruitment and the dynamics of communities of coral reef fishes. Mar Biol 117:33-43

Caley JM, St John J (1996) Reluge availability structures assemblages of tropical reef fishes. I Anim Ecol 65:414-428

Chabanet P, Dufour V, Galzin R (1995) Disturbance impact on reef fish communities in Reunion Island (Indian Ocean). J Exp Mar Biol Ecol 188:29-48

Dawson Shepard AR, Warwick RM, Clarke KR, Brown BE (1992) An analysis of fish community responses to coral mining in the Maldives. Envir on Biol Fishes 33:367-380

Doherty PJ (1983) Tropical territorial damselfishes: is density limited by aggression or recruitment? Ecology 64:176-190

Done $T$ (1992) Constancy and change in some Great Barrier Reef coral communities: 1980-1990. Am Zool 32:655-662

Dutilleul P (1993) Spatial heterogeneity and the design of ecological field experiments. Ecology 74 (6):1646-1658

Findley JS, Findley MT (1985) A search for pattern in butterflyfish communities. Am Nat 126:800-816

Fowler AJ (1990) Spatial and temporal patterns of distribution and abundance of chaetodontid fishes at One Tree Reef, southern GBR. Mar Ecol Prog Ser 64:39-53

Green AL (1996) Spatial, temporal, and ontogenetic patterns of habitat use by coral reef fishes (Family Labridae). Mar Ecol Prog Ser 133:1-11

Green RH (1979) Sampling design and statistical methods for environmental biologists. Wiley, New York

Green RH (1993) Application of repeated measures designs in environmental impact and monitoring studies. Aust J Ecol 18:81-98

Hixon MA. Beets JP (1993) Predation, prey refuges, and the structure of coral-reef fish assemblages. Ecol Monogr $63(1): 77-101$

Hourigan TF, Tricas TC, Reese ES (1988) Coral reef fishes as indicators of environmental stress in coral reefs. In: Soule DF, Kleppel GS (eds) Marine organisms as indicators. Springer-Verlag, New York, p 107-136

Hurlbert SH (1984) Pseudoreplication and the design of ecological field experiments. Ecol Monogr 54(2):187-211

Jennrich RI, Schluchter MD (1986) Unbalanced repeated measures models with structured covariance matrices Biometrics 42:805-820

Jones GP (1988) Experimental evaluation of the effects of habitat structure and competitive interactions on the juveniles of two coral reef fishes. J Exp Mar Biol Ecol 123: $115-126$

Jones GP (1991) Post-settlement processes in the ecology of coral reef fish populations: a multi factorial perspective. In: Sale PF (ed) The ecology of fishes on coral reefs. Academic Press, San Diego, p 294-328

Jones GP, Kaly UL (1996) Criteria for selecting marine organisms in biomonitoring studies. In: Schmitt RJ, Osenberg $\mathrm{CW}$ (eds) Detecting ecological impacts: concepts and applications in coastal habitats. Academic Press, New York, p 29-48

Kaufman LS (1983) Effects of hurricane Allen on reef fish assemblages near Discovery Bay, Jamaica. Coral Reefs 2: $43-47$ 
Kuiter RH (1992) Tropical reef fishes of the Western Pacific, Indonesia, and adjacent waters. PT Gramedia Pustaka Utama, Jakarta

Laird NM, Ware JH (1982) Random effects models for long1tudinal data. Biometrics 38:963-974

Lassig BR (1983) The effects of a cyclonic storm on coral reef fish assemblages. Environ Biol Fishes 9\{1\}:55-63

Lewis AR (1997) Recruitment and post-recruit immigration affect the local population size of coral reef fishes. Coral Reefs 16:139-149

Lindstrom MJ, Bates DM (1990) Nonlinear mixed effects models for repeated measures data. Biometrics 46: $673-687$

Luckhurst BE, Luckhurst K (1978) Analysis of the influence of substrate variables on coral reef fish communities. Mar Biol 49:317-323

McCormick MI (1995) Fish feeding on mobile benthic invertebrates: influence of spatial variability in habitat associations. Mar Biol 121:627-637

Ormond RFG, Roberts JM, Jan RQ (1996) Behavioural differences in microhabitat use by damselfishes (Pomacentridae): implications for reef fish biodiversity. J Exp Mar Biol Ecol 202:85-95

Randall JE, Allen GR, Steene RC (1990) Fishes of the Great Barrier Reef and Coral Sea. Crawford House Press, Bathurst

Roberts CM, Ormond RFG (1987) Habitat complexity and coral reef fish diversity and abundance on Red Sea fringing reefs. Mar Ecol Prog Ser 41:1-8

Sale PF, Douglas WA (1984) Temporal variability in the community structure of fish on coral patch reefs and the rela-

Editorial responsibility: George Humphrey (Contributing Editor), Sydney, Australia tion of community structure to reef structure Ecology $65(2) \cdot 409-422$

Sano M. Shimizu M, Nose Y (1987) Long-term effects of destruction of hermatypic corals by Acanthaster planci infestation on reef fish communities at Iriomote Island, Japan. Mar Ecol Prog Ser 37:191-199

Tanner JE, Hughes TP, Connell JH (1994) Species coexistence, keystone species, and succession: a sensitivity analysis. Ecology 75(8):2204-2219

Tanner JE, Hughes TP, Connell JH (1996) The role of history in community dynamics: a modelling approach. Ecology $77(1): 108-117$

Tolimieri $N$ (1995) Effects of microhabitat characteristics on the settlement and recruitment of a coral reef fish at two spatial scales. Oecologia 102:52-63

Underwood AJ (1992) Beyond BACI: the detection of environmental impacts on populations in the real, but variable, world. J Exp Mar Biol Ecol 161:145-178

Warwick RM, Clarke KR (1991) A comparison of some methods for analysing changes in benthic community structure. J Mar Biol Assoc UK 71:225-244

Williams DMcB (1986) Temporal variation in the structure of reef slope fish communities (central Great Barrier Reef): short-term effects of Acanthaster planci infestation. Mar Ecol Prog Ser 28:157-164

Williams DMcB, Sale PF (1981) Spatial and temporal patterns of recruitment of juvenile coral reef fishes to coral habitats within 'One Tree Lagoon', Great Barrier Reef. Mar Biol 65: $245-253$

Zar JH (1984) Biostatistical analysis, 2nd edn. Prentice Hall, Englewood Cliffs, NJ

Submitted: May 12, 1997; Accepted: October 15, 1997 Proofs received from author(s): December 15, 1997 